\title{
SEROPREVALENCIA DE Toxoplasma gondii EN ALPACAS HEMBRAS DE LA SAIS PACHACÚTEC, SIERRA CENTRAL DEL PERÚ
}

\author{
Seroprevalence of Toxoplasma gondi in Females Alpacas of SAIS \\ Pachacutec, Central Sierra of Peru
}

\author{
Hernán De La Cruz C. ${ }^{1}$, Amanda Chávez V. ${ }^{1,2}$, Eva Casas A. ${ }^{1}$, Olga Li E. ${ }^{3}$
}

\section{RESUMEN}

El objetivo del estudio fue determinar la seroprevalencia de anticuerpos antiToxoplasma gondii en alpacas de la Unidad de Producción de Cuyo de la SAIS Pachacútec, ubicada en la Sierra Central del país. En enero de 2003 se tomaron muestras de sangre a 258 alpacas hembras para la detección de anticuerpos de $T$. gondii, mediante la técnica de Inmunofluorescencia Indirecta (IFI). Se encontró que el $8.5 \pm 3.4 \%(22 / 258)$ de las muestras presentaban anticuerpos contra el parásito; frecuencia menor que en otras zonas alpaqueras del país.

Palabras clave: camélidos, $T$. gondii, anticuerpos, inmunofluorescencia, prevalencia

\section{Abstract}

The objective of this study was to determine the seroprevalence of antibodies against Toxoplasma gondii in alpacas at the production unit of Cuyo, part of SAIS Pachacutec in the Central Sierra of Peru. Blood samples were collected in 258 female alpacas in January 2003. Sera were tested against $T$. gondii antibodies by the Indirect Immunoflorescence test (IFI). The results showed that $8.5 \pm 3.4 \%(22 / 258)$ of animals had antibodies against the parasite. This frequency is lower than in other alpaca breeding regions of the country.

Key words: camelides, $T$. gondii, antibodies, immunofluorescence, prevalence

\footnotetext{
${ }^{1}$ Laboratorio de Microbiología y Parasitología Veterinaria, ${ }^{3}$ Laboratorio de Patología Clínica y Biología Molecular, Facultad de Medicina Veterinaria, Universidad Nacional Mayor de San Marcos, Lima

${ }^{2}$ E-mail: achavezvg@gmail.com
} 


\section{INTRODUCCIÓN}

La toxoplasmosis es una de las infecciones parasitarias de mayor difusión a nivel mundial. Es producido por Toxoplasma gondii, protozoario cuyo hospedero definitivo es el gato y los hospederos intermediarios son todas las especies de mamíferos y aves. El $T$. gondii constituye un agente causal de infertilidad, esterilidad, aborto, y mortalidad embrionaria y perinatal en ovinos y caprinos.

En el Perú, estudios de seroprevalencia han sido realizados en ovinos, caprinos y porcinos (Rojas, 1990; Suárez et al., 2004). Los trabajos se seroprevalencia en camélidos sudamericanos (CSA) reportan frecuencias de $35 \%$ (Suárez et al., 2004), 10\% (Saravia et al., 2004) y 15\% (Pastor et al., 2003) en alpacas, llamas y vicuñas, respectivamente. A pesar de ello, hasta el momento no se ha podido determinar los problemas reproductivos que podría causar, tal y como ocurre en ovinos y caprinos, pese a que desde hace muchos años se ha visto la necesidad de determinar la importancia de la toxoplasmosis en los CSA (Fernández-Baca, 1991).

El presente estudio tuvo por objetivo determinar la presencia de anticuerpos contra $T$. gondii en el suero de alpacas hembras en una localidad de la Sierra Central del Perú.

\section{Materiales y Métodos}

El presente estudio se llevó a cabo en enero del 2003 en la Unidad de Producción de Cuyo de la Sociedad Agraria de Interés Social (SAIS) Pachacútec, ubicada en el distrito de Marcopomacocha, provincia de Yauli, departamento de Junín, ubicado a 4200 msnm.

El tamaño muestral $(\mathrm{n}=258)$ se determinó mediante la fórmula de proporciones en poblaciones finitas (Daniel, 1996). La muestra se distribuyó en 4 grupos etarios $(8-12,>12-$ $24,25-36$ y $>36$ meses). Se recolectaron 258 muestras de sangre de alpacas hembras, aparentemente sanas. El suero fue separado por centrifugación y transportado al Laboratorio de Parasitología de la Facultad de Medicina Veterinaria de la Universidad Nacional Mayor de San Marcos, Lima, donde fue guardado a $-20^{\circ} \mathrm{C}$.

Se determinó el nivel de anticuerpos cantra $T$. gondii mediante la prueba de Inmunofluorescencia Indirecta (IFI) a una dilución 1:200 (Chávez et al., 2005). Las muestras se consideraron positivas al observar la fluorescencia en todo el contorno del taquizoito y negativas si hubo fluorescencia parcial o nula. Los resultados se expresaron en porcentaje con su respectivo intervalo de confianza.

\section{Resultados y Discusión}

La seroprevalencia en alpacas fue de $8.5 \pm 3.4 \%$ (Cuadro 1). Este resultado confirma la presencia del parásito en la zona de muestreo, aunque con una frecuencia menor que en otras zonas del país. Leguía et al. (1987) y Gómez et al. (2003), mediante la técnica de hemoaglutinación indirecta (HAI), reportaron prevalencias de 50 y $45 \%$ en alpacas de la sierra sur del país, respectivamente; en tanto que Góngora (1992) en Puno, y Ramírez et al (2005) en Cusco encontraron prevalencias de 24 y $36 \%$, respectivamente, empleando la prueba de IFI.

No se encontró diferencias estadísticas por grupo etario (Cuadro 1); sin embargo, se nota un ligero incremento en la presentación de anticuerpos de acuerdo a la edad, toda vez que a mayor edad existe un mayor tiempo de exposición y, por lo tanto, una mayor probabilidad de infección (Ramírez et al., 2005; Valencia. 2006).

Las razones por una seroprevalencia baja podría deberse a la escasa presencia del 
Cuadro 1. Seroprevalencia de Toxoplasma gondii en alpacas de la Unidad de Producción de Cuyo de la SAIS Pachacútec-Junín, según grupo etario (2003)

\begin{tabular}{|c|c|c|c|}
\hline \multirow{2}{*}{$\begin{array}{c}\text { Edad } \\
\text { (meses) }\end{array}$} & \multirow{2}{*}{$\begin{array}{c}\text { Animales } \\
\text { muestreados }\end{array}$} & \multicolumn{2}{|c|}{ Animales seropositivos } \\
\hline & & N. ${ }^{\circ}$ & $\% \pm$ I.C. $^{1}$ \\
\hline 8 a 12 & 21 & 1 & $4.8 \pm 9.1$ \\
\hline$>12$ a 24 & 24 & 1 & $4.2 \pm 8.0$ \\
\hline$>24$ a 36 & 26 & 3 & $11.5 \pm 12.3$ \\
\hline$>36$ & 187 & 17 & $9.1 \pm 4.1$ \\
\hline Total & 258 & 22 & $8.5 \pm 3.4$ \\
\hline
\end{tabular}

hospedero definitivo, tipo de manejo de los animales, y lejanía con centros poblados y carreteras. Las alpacas de la unidad de producción bajo estudio se encuentran bajo un sistema de manejo cerrado, donde las faenas de parición, esquila, y dosificaciones se realizan en la misma área. En cambio, en la zona sur del país, que alberga la mayor población de camélidos, las alpacas son criadas bajo un sistema de manejo abierto, donde son trasladadas a áreas centrales y comunes para realizar las actividades de manejo; y esto conlleva un mayor estrés y cercanía a poblaciones humanas donde existe mayor probabilidad de hallar felinos domésticos y pasturas contaminados con heces de gatos conteniendo ooquistes de $T$. gondii.

Información obtenida de los pobladores de la zona de muestreo señala un escaso número de gatos domésticos y de felinos silvestres. Al parecer, las alpacas de la Sierra Central del país están menos propensas a la toxoplasmosis, pues Poma (2003) en la zona de Junín encontró $23 \%$ de seroprevalencia a T. gondii, frecuencia menor a la reportada en la zona alpaquera del sur del país (Suárez et al., 2004: Ramírez et al., 2005). Por otro lado, las zonas de pastoreo en el presente estudio se hallaban alejadas de zonas pobladas, el acceso era difícil y, por tanto, las probabili- dades de diseminación del parásito fueron menores a las encontradas en el estudio realizado por Poma (2003).

En trabajos publicados por Poma (2003) en Junín y Valencia (2006) en Huancavelica se empleó la técnica de HAI, mientras que en el presente estudio se utilizó la técnica de IFI estandarizada para alpacas, en una dilución de 1/200 y no de 1/50 como era utilizada anteriormente en las evaluaciones de CSA, ya que ocasionaba una sobreestimación de la infección (Chávez et al., 2005).

\section{Conclusión}

La seroprevalencia en alpacas hembras de la unidad de producción de Cuyo, SAIS Pachacutec fue baja $(8.5 \pm 3.4 \%)$.

\section{Literatura Citada}

1. Chávez A, Álvarez G, Gómez M, Casas E, Serrano E, Ortega L. 2005. Toxoplasma gondii in adult llamas (Lama glama) and vicunas (Vicugna vicugna) in the Peruvian Andean region. Vet Parasitol 130: 93-97. 
2. Daniel W. 1996. Bioestadística base para el análisis de las ciencias de la salud. $5^{\text {a }}$ ed. México: Ed. Limusa. 878 p.

3. Gómez O, Chávez A, Casas E, Serrano E, Cárdenas O. 2003. Determinación de la seroprevalencia de toxoplasmosis en alpacas y llamas en la estación experimental INIA-Puno. Rev Inv Vet, Perú 14(1): 49-53.

4. Góngora M. 1992. Prevalencia de anticuerpos contra Toxoplasma gondii en las comunidades Alpaqueras de Vilcallamas, Bajo Llallagua, Huanacayama y Llusta. Tesis de Médico Veterinario y Zootecnista. Puno: Univ. Nac. del Altiplano. $47 \mathrm{p}$.

5. Leguía G, Samamé H, Guerrero C, Rojas M, Núñez A. 1987. Prevalencia de anticuerpos contra $T$. gondii el alpacas. Rev Cienc Vet 3: 19-21.

6. Leguía G. 1991. Enfermedades parasitarias. En: Fernández-Baca S (ed). Avances y perspectivas del conocimiento de los camélidos sudamericanos. Santiago de Chile: FAO. p 325-362.

7. Pastor J, Chávez A, Casas E, Serrano E. 2003. Seroprevalencia de $T$. gondii en vicuñas de Puno. Rev Inv Vet, Perú 14(1): 79-82.
8. Poma E. 2003. Seroprevalencia de Toxoplasma gondii en alpacas (Lama pacos) en una unidad de producción de la sierra central del Perú. Tesis de Médico Veterinario. Lima: Univ Nacional Mayor de San Marcos. 57 p.

9. Ramírez J, Chávez A, Casas E, Rosadio R, Falcón N. 2005. Seroprevalencia de Toxoplasma gondii en alpacas de comunidades de la provincia de Canchis, Cusco. Rev Inv Vet, Perú 16: 169-174.

10. Rojas M. 1990. Parasitismo de los rumiantes domésticos: terapia, prevención y modelos para su aprendizaje. Lima: Mijosa. 348 p.

11. Saravia M, Chávez A, Casas E, Falcón N, Pinto W. 2004. Seroprevalencia de Toxoplasma gondii en llamas de una empresa pecuaria de Melgar, Puno. Rev Inv Vet, Perú 15: 49-55.

12. Suárez F, Flores W, Chávez A, Rivera H, Huanca W. 2004. Toxoplasmosis en alpacas de la Sierra Altoandina. Rev Inv Vet, Perú 15: 170-173.

13. Valencia N. 2006. Toxoplasmosis como agente causal de abortos en alpacas. Tesis de Maestría. Lima: Univ Nacional Mayor de San Marcos. 91 p. 